\title{
Functional Outcome of Bipolar Hemiarthroplasty for Proximal Femoral Neck Fractures in Elderly: A Prospective Study
}

\author{
Vijayanand Ramasamy ${ }^{1}$, Rajkumar Nallan ${ }^{2}$
}

\begin{abstract}
Aim and background: Hip fractures are the most frequently seen injuries by orthopedic surgeons and are particularly prevailing in the geriatric community. This study was performed to evaluate the efficacy of the bipolar hemiarthroplasty among elderly patients with a proximal femoral neck fracture.

Materials and methods: This was a prospective study undertaken at the Department of Orthopedic Surgery at a tertiary care institute from January 2014 to December 2015. The patients were selected based on the convenience sampling (Judgment sampling) method. Bipolar hemiarthroplasty was performed. The majority had cemented implants, with three having uncemented. Functional outcome was assessed periodically at 6 weeks, 3 months, 6 months, and 1 year using modified Harris hip scoring system using coGuide for statistical analysis and $p$ value set at 0.05 .

Results: A total of 43 patients $>50$ years of age with 23 (54.5\%) males and 20 (45.5\%) females, among which 39 (90.69\%) with fractured neck of femur and $4(9.31 \%)$ with trochanteric fracture were studied. Forty (93\%) had cemented implants. Harris hips ROM score 5 was noted in $50 \%$ of the participants, scores 4 and 3 in 42.5 and $7.5 \%$, respectively. Excellent functional score was noted in 16 (40\%), good in 18 (45\%), satisfactory in 3 (7.5\%), and $3(7.5 \%)$ had poor score. Only two (5\%) participants had radiolucent zone $>2 \mathrm{~mm}$ and one ( $2.5 \%)$ had subsidence of prosthesis $>5 \mathrm{~mm}$. Conclusion: Cemented bipolar hemiarthroplasty is present in mobile geriatric patients above 50 years of age with a proximal femoral neck fracture. Clinical significance: A bipolar hemiarthroplasty is a reliable option in treating fracture neck of femur in the elderly with several comorbidities. All the participants had a sufficient functional outcome in regular daily activity, less hospital stay, residual pain, postoperative functionality, and fewer postoperative complications. It can be used in day-to-day clinical practice.

Keywords: Bipolar hemiarthroplasty, Elderly patients, Harris hip score, Proximal femoral neck fracture, Trochanteric fracture.

Journal of Orthopedics and Joint Surgery (2022): 10.5005/jp-journals-10079-1053
\end{abstract}

\section{INTRODUCTION}

Hip fractures are the most frequently seen injuries by orthopedic surgeons and are particularly prevailing in the geriatric community. Over one-third of the adult population of age 65 and above experience a fall each year. ${ }^{1}$ Among all types of hip fractures, intertrochanteric hip fractures make up $45 \%$ making it majorly observed hip fractures. ${ }^{2}$ In geriatric patients, displaced femoral neck fractures are considered fatal injuries. They not only decrease the quality of life but also are related to morbidity and cause an increase in the risk of death. ${ }^{3}$ In the year 1990, the incidence was estimated to be 1.66 million with a probability of increasing up to 6.26 million in 2050, because of the increasing longer duration of life of the geriatric population. ${ }^{4}$ For the treatment of these fractures, there are various options available which include hemiarthroplasty, total hip arthroplasty, and internal fixation. ${ }^{5}$ As per surveys conducted in the past, hemiarthroplasty is considered to be the most accepted treatment option by surgeons. ${ }^{5,6}$ Professionals supporting hemiarthroplasty consider that the rate of nonunion is increased with age. This higher need for early reoperation is associated with fixation making replacement a more dependable and proven choice of treatment for the geriatric population. Hemiarthroplasty causes speedy recovery of mobility and delayed issues of loosening and wear are of lower concern in patients with a short lifespan. The treatment targets for femoral neck fractures timely return to an adequate functional status along with the decline in morbidity, mortality, and the need for reoperation. ${ }^{6}$ Bipolar hemiarthroplasty has an extra inner bearing between the endoprosthetic head component and the stem. Theoretically, this
1,2Department of Orthopaedic Surgery, Dhanalakshmi Srinivasan Medical College and Hospital, Perambalur, Tamil Nadu, India

Corresponding Author: Vijayanand Ramasamy, Department of Orthopaedic Surgery, Dhanalakshmi Srinivasan Medical College and Hospital, Perambalur, Tamil Nadu, India, Phone: +91 9940275574, e-mail: dr.vijayanand12@gmail.com

How to cite this article: Vijayanand RR, Rajkumar N. Functional Outcome of Bipolar Hemiarthroplasty for Proximal Femoral Neck Fractures in Elderly: A Prospective Study. J Orth Joint Surg 2022;4(1):22-25.

Source of support: Nil

Conflict of interest: None

design would decrease protrusion, dislocation, and acetabular erosion. It also maintains the stability of the joint and increases hip function. ${ }^{7,8}$ Cemented fixation has an advantage as it enhances the initial fixation strength among geriatric with poor bone quality, on the other hand, cementless fixation encourages biological fixation and can reduce cardiovascular toxicity. ${ }^{9}$ It can be said that for unstable intertrochanteric fractures in the older population bipolar hemiarthroplasty is an enduring and adaptable solution. ${ }^{10}$

Fixation loss, excessive collapse, and cut-out of the lag screw causing poor function remain an issue related to internal fixation of unstable intertrochanteric fracture in the geriatric patients having osteoporotic bones. Studies show that several surgeons recommend a prosthetic replacement for the treatment of unstable intertrochanteric fractures to enable the earlier postoperative weight-bearing as well as to prevent excessive collapse at the site

(c) The Author(s). 2022 Open Access This article is distributed under the terms of the Creative Commons Attribution 4.0 International License (https://creativecommons. org/licenses/by-nc/4.0/), which permits unrestricted use, distribution, and non-commercial reproduction in any medium, provided you give appropriate credit to the original author(s) and the source, provide a link to the Creative Commons license, and indicate if changes were made. The Creative Commons Public Domain Dedication waiver (http://creativecommons.org/publicdomain/zero/1.0/) applies to the data made available in this article, unless otherwise stated. 
of fracture. ${ }^{1}$ Lehtonen et al., in their study, found that cemented bipolar arthroplasty is an alternative in freely mobile geriatric patients above 70 years of age with an intertrochanteric femoral fracture as it permits postoperative full weight-bearing, thus sparing the patients from the postoperative impediments of non-weight bearing post internal fixation. ${ }^{1}$ In the current study, elderly patients undergoing bipolar hemiarthroplasty for osteoporotic proximal femoral fractures were reviewed regularly at 6 weeks, 3 months, 6 months, and 1-year post-surgery to evaluate the functional outcome using Harris hip score.

The purpose of this prospective study is to evaluate the shortterm functional outcome of bipolar hemiarthroplasty for the management of proximal femoral fractures in patients of 50 years and above.

\section{Aims and Objectives}

To study the short-term functional outcome of bipolar hemiarthroplasty for the management of proximal femoral fractures in patients of 50 years and above.

\section{Materials and Methods}

This was a prospective experimental study carried out at the Department of Orthopedic Surgery at a tertiary care institute from January 2014 to December 2015, Chennai. This study includes 43 cases of hip fractures (displaced fracture neck of femur and trochanteric fractures) in elderly above 50 years of age of both sexes treated by bipolar hemiarthroplasty. The participants were allocated based on the convenience sampling (Judgment sampling) method. The study included 23 males and 20 females. The age ranged from 50 to 90 years, the average being 70.1 years. Patients with preexisting sepsis, active young patients with fractured neck of femur, neuropathic arthropathy, and individuals bedridden before injury were excluded from the study.

\section{Surgical Procedure}

Under regional anesthesia, the prophylactic antibiotic was given. The patient was positioned lateral, and through a posterior approach, the hip joint was reached, and posterior capsulotomy was done. The fractured femoral head was dislocated and removed. Head size was measured. The neck was trimmed to the appropriate length. Femoral canal prepared. Serial broaching done. Trial implant inserted. In the case of an uncemented implant, 2-3 $\mathrm{mm}$ of medullary bone was preserved, and the original uncemented porous-coated stem was inserted. For cementation, thorough saline lavage was given, and debris was removed and dried. Using methyl methacrylate cement, a femoral prosthesis was inserted. The offset, which gives adequate motion and stability, was fixed and hip reduced and stability and range of movements checked.

\section{Postoperative Protocol}

The patients were admitted to a postoperative ward. Positioning of the hip was placed in approximately $15^{\circ}$ of abduction using an abduction pillow in the immediate postoperative period. On the first postoperative day, bed exercises and limited mobilization were initiated. Quadriceps, deep breathing, and glutei isometrics, and gentle rotation exercises were started. Parenteral antibiotics were given for the first 3 days. Suture removal was done postoperative 10 days. The patient was motivated to do full weight-bearing walking in the first or second postoperative days. In the uncemented version, the patients were allowed non-weight-bearing crutch walking for 6 weeks and, after radiological assessment, protected weight-bearing for approximately 12 weeks.

Once the patient was admitted to the hospital, all the required information was recorded in the proforma prepared for the current study. The follow-up was carried out at an interval of 6 weeks, 3 months, 6 months, and 1 year. The follow-up chart of the proforma was maintained to keep a record of the follow-ups. At the end of the study, the patients were called back for final review during the months of December 2015 through telephone and post. Patients were reassessed clinically using the Harris hip score during the follow-up period and on final review. A comparison was done of initial X-rays of the hip and the newly taken for signs of migration, loosening, $\mathrm{X}$-rays of the hip were taken and were compared with the initial X-rays for signs of wear, and implant failure. The duration of follow-up, at the end of this study, ranged from 6 to 18 months, with an average of 14.2 months. Functional outcome scores were the primary outcome variable.

\section{Statistical Methods}

Descriptive analysis was performed by the mean and standard deviation for quantitative variables, frequency, and proportion for categorical variables. coGuide was used for statistical analysis. ${ }^{11}$

\section{Results}

A total of 43 subjects were included in the final analysis.

The majority of 15 (34.8\%) study participants were aged between 71 years and 80 years, followed by $61-70$ and $50-60$ years age group was 30.2 and $18.7 \%$, respectively. In the study participants, 23 (54.5\%) were males, and the remaining 20 (45.5\%) participants were females. Among the people with indication, 39 (90.69\%) participants had the fractured neck of femur, and 4 (9.31\%) participants had a trochanteric fracture. Among the study population, 40 (93\%) participants had cemented implants.

In our study, there were 39 patients with fractured neck of femur and 4 patients with trochanteric fractures. Displaced femoral neck fractures predominated our study (Table 1). The majority of

Table 1: Summary of baseline characteristics

\begin{tabular}{lcc}
\hline Parameter & No. of patients & Percentage \\
\hline Age group, years & & \\
$50-60$ & 8 & 18.7 \\
$61-70$ & 13 & 30.2 \\
$71-80$ & 15 & 34.8 \\
$\quad>80$ & 7 & 16.3 \\
Gender & & \\
$\quad$ Male & 23 & 54.5 \\
$\quad$ Female & 20 & 45.5 \\
Types of fracture & & \\
Indications & & \\
$\quad$ Fracture neck of & 39 & 90.69 \\
femur & & \\
$\quad$ Trochanteric & 4 & 9.31 \\
fracture & & \\
Implants & & 93.0 \\
$\quad$ Cemented & 40 & 07.0 \\
$\quad$ Uncemented & 03 &
\end{tabular}


Table 2: Distribution of the sample by range of movement

\begin{tabular}{lccc}
\hline$R O M$ & Score & Frequency $(n=40)$ & Percentage \\
\hline $211-300^{\circ}$ & 5 & 20 & 50 \\
$161-210^{\circ}$ & 4 & 17 & 42.5 \\
$101-160^{\circ}$ & 3 & 3 & 7.5 \\
$61-100^{\circ}$ & 2 & 0 & 0 \\
$31-60^{\circ}$ & 1 & 0 & 0 \\
$0-30^{\circ}$ & 0 & 0 & 0 \\
\hline
\end{tabular}

Table 3: Functional outcome

\begin{tabular}{lcc}
\hline Functional results & Frequency $(n=40)$ & Percentage \\
\hline Excellent (91-100) & 16 & 40 \\
Good (81-90) & 18 & 45 \\
Satisfactory (71-80) & 3 & 7.5 \\
Poor $(\leq 70)$ & 3 & 7.5 \\
\hline
\end{tabular}

Table 4: Distribution of the sample by radiographic results at the final assessment $(n=40)$

\begin{tabular}{lcc}
\hline Findings & Frequency & Percentage \\
\hline Femoral stem & & \\
1. Radiolucent zone $>2 \mathrm{~mm}$ & 2 & 5 \\
2. Subsidence of prosthesis $>5 \mathrm{~mm}$ & 1 & 2.5 \\
3. Sclerosis at the tip of the prosthesis & 0 & 0 \\
Acetabulum & & \\
1. Erosion & 0 & 0 \\
2. Protrusion & 0 & 0 \\
Heterotopic ossification & 0 & 0 \\
Dislocation/subluxation & 0 & 0 \\
Total & 3 & 0 \\
\hline
\end{tabular}

patients (92.5\%) had a good to an excellent range of movements on final follow-up (Table 2).

Among the people with a functional score, 16 (40\%) participants had excellent, 18 (45\%) participants had good, and 3 (7.5\%) participants had satisfactory and poor for each, respectively (Table 3).

Among the study population, two (5\%) participants had radiolucent zone $>2 \mathrm{~mm}$, and only one (2.5\%) participant had subsidence of prosthesis $>5 \mathrm{~mm}$ (Table 4).

\section{Discussion}

As per the literature and theories from the past, bipolar hemiarthroplasties were found to tackle the complications of unipolar implants such as protrusion, acetabular wear, dislocation, and loosening. Stems were reorganized, more in line with total hip replacement designs, to decrease component loosening. To initiate the reduction of acetabular wear and dislocation rates, the inner bearing motion was introduced. ${ }^{12}$ With the reference to past studies, the present study was carried out to evaluate functional outcomes in bipolar hemiarthroplasty as the primary treatment of choice among elderly patients with a proximal femoral neck fracture.

In our study population, the majority age was 90 years in the case of males and 87 years in the case of females. The majority of the patients were in the age group of 71-80 years, with a mean age of 70.1 years. There were 20 female patients and 23 male patients showing preponderance of males over females. In a similar study by Saoudy and Salama, there were 22 men and 8 women with a mean age of 60 years (range: $55-70$ years). ${ }^{13}$ Displaced femoral neck fractures predominated our study, and all underwent bipolar hemiarthroplasty, of which 40 were cemented and 3 uncemented. Harris hip ROM score of 5 was noted in $50 \%$ of the participants, score 4 in $42.5 \%$, and score 3 in $7.5 \%$. The total Harris hip score at the end of the final assessment ranged from 55 to 97 . Among the study population, $40 \%$ had excellent Harris hip scores, $45 \%$ good, $7.5 \%$ satisfactory, and $7.5 \%$ poor. Thus, $92.5 \%$ of the patients were classified as having a satisfactory to excellent result, and $7.5 \%$ of the patients had a poor result. We compared the results of this study with the results obtained by other studies, in the Vala et al.' $\mathrm{s}^{10}$ study group at the end of 9 months, $24 \%$ had excellent results, $60 \%$ had good results, $12 \%$ had fair results, and $4 \%$ had poor result. In Patil et al.'s study, the functional outcome was reported to be excellent among $29.0 \%$ of the study group, fair in $25.8 \%$, good in $32.3 \%$, and poor in $9.7 \% .^{14}$

There were two cases with a radiolucent zone $>2 \mathrm{~mm}$ around the stem of the prosthesis. Subsidence of the prosthesis was found in one case. $22.5 \%$ of patients had limb length shortening. In Saoudy and Salama's study, complications were reported in four cases, two of them being a superficial infection, loosening in one patient, and acetabular wear in one patient. ${ }^{13}$

The present study provided good results, with the achievement of remarkable functional ability and pain control. The majority of patients had regained good walking distance, were able to climb stairs, sit comfortably in an ordinary chair. According to our results, it can be suggested that cemented bipolar hemiarthroplasty is a better option in freely mobile elderly patients above 50 years of age with a proximal femoral neck fracture.

\section{Conclusion}

Most of the participants in the study with proximal femoral neck fracture treated with bipolar hemiarthroplasty had a short hospital stay, less pain, no lasting limp, early mobilization, early return to pre-injury level, and a superior quality of life. It can be concluded from the current research that bipolar hemiarthroplasty is a successful treatment for the proximal neck of femur fractures in the geriatric population. Limitations include small sample size and relatively short-term follow-up as for assessment of implantrelated complications, studies with a longer duration of follow-up are recommended in the future.

\section{References}

1. Lehtonen EJI, Stibolt Jr RD, Smith W, et al. Trends in the surgical treatment of femoral neck fractures in the elderly. Einstein 2018;16(3):eAO4351. DOI: 10.1590/s1679-45082018ao4351.

2. Parker M, Johansen A. Hip fracture. BMJ 2006;333((7557)):27-30. DOI: 10.1136/bmj.333.7557.27

3. Kristensen TB, Dybvik E, Kristoffersen $M$, et al. Cemented or uncemented hemiarthroplasty for femoral neck fracture? data from the norwegian hip fracture register. Clin Orthop Relat Res 2020;478(1):90-100. DOI: 10.1097/corr.0000000000000826

4. Reddy GR, Prasad PN. Efficacy of bipolar hemiarthroplasty in the elderly people: a study in a tertiary care centre. Int J Res Orthop 2017;3(3):396 DOI: 10.18203/issn.2455-4510.IntJResOrthop20171573

5. lorio R, Schwartz B, Macaulay W, et al. Surgical treatment of displaced femoral neck fractures in the elderly: a survey of the American Association of Hip and Knee Surgeons.J Arthroplast 2006;21(8):11241133. DOI: 10.1016/j.arth.2005.12.008

6. Bhandari M, Devereaux PJ, Tornetta P, et al. Operative management of displaced femoral neck fractures in elderly patients. An international survey. J Bone Jt Surg Am 2005;87(9):2122-2130. DOI: 10.2106/ jbjs.e.00535 
7. Bhattacharyya T, Koval KJ. Unipolar versus bipolar hemiarthroplasty for femoral neck fractures: is there a difference?J Orthop Trauma 2009;23(6):426-427. DOI: 10.1097/BOT.0b013e3181adb057

8. Gilbert MS, Capozzi J. Unipolar or bipolar prosthesis for the displaced intracapsular hip fracture? an unanswered question. Clin Orthop Relat Res 1998(353):81-85. DOI: 10.1097/00003086-199808000-00010

9. Choy WS, Ahn JH, Ko JH, et al. Cementless bipolar hemiarthroplasty for unstable intertrochanteric fractures in elderly patients. Clin Orthop Surg 2010;2(4):221-226. DOI: 10.4055/cios.2010.2.4.221

10. Vala P, Shah R, Gandhi T, et al. Outcomes of primary bipolar hemiarthroplasty in the management of unstable inter-trochanteric fracture of femur among elderly. IntJ Orthop 2019;5(2):739-743. DOI: 10.22271 /ortho.2019.v5.i2k.81
11. BDSS Corp. Released 2020. coGuide Statistics software, Version 1.0, India: BDSS corp.

12. Wathne RA, Koval KJ, Aharonoff GB, et al. Modular unipolar versus bipolar prosthesis: a prospective evaluation of functional outcome after femoral neck fracture. J Orthop Trauma 1995;9(4):298-302. DOI: 10.1097/00005131-199509040-00005

13. Saoudy EE, Salama AM. Bipolar hemiarthroplasty for the treatment of unstable trochanteric fracture femur in the elderly. Egypt Orthop J 2016;51(4):313

14. Patil V, Nandi SS, Naik S, et al. Functional outcome of unstable comminuted intertrochanteric fractures in elderly treated with primary bipolar hemiarthroplasty. IntJ Orthop 2019;5(1):59-62. DOI: 10.22271/ortho.2019.v5.i1b.13 